\title{
New onset atrial fibrillation after initiating amphetamine-dextroamphetamine therapy for ADHD: A case report
}

\author{
Aimee Wehber*1, Jeffrey Hirsh ${ }^{2}$ \\ ${ }^{1}$ Graduate School of Medicine, University of Tennessee Medical Center, Tennessee, USA \\ ${ }^{2}$ University Cardiology, University of Tennessee Medical Center, Heart Lung Vascular Institute, Tennessee, USA
}

Received: October 20, 2015

DOI: $10.5430 /$ crim.v3n1p33
Accepted: November 10, 2015 Online Published: December 14, 2015

URL: http://dx.doi.org/10.5430/crim.v3n1p33

\begin{abstract}
Atrial fibrillation is a common arrhythmia in the general population, and is expected to significantly increase in prevalence in the near future. This case illustrates a 50-year-old male who developed atrial fibrillation after starting amphetaminedextroamphetamine for attention deficit hyperactivity disorder (ADHD), with no previous history of structural heart disease. Central nervous system stimulant medications have significant cardiovascular implications and at risk patients should be monitored closely. Additionally, identifying causative agents for atrial fibrillation and other arrhythmias is imperative, as there is a significant association with morbidity and mortality.
\end{abstract}

Key Words: Atrial fibrillation, Amphetamine, Attention deficit hyperactivity disorder, Stimulants

\section{INTRODUCTION}

Atrial fibrillation is a very common rhythm in the general population, with a prevalence of approximately $2 \%$, with the majority of the patients being of older age. ${ }^{[1]}$ Wellestablished risk factors for atrial fibrillation include congestive heart failure, hypertension, diabetes mellitus, hyperthyroidism, structural heart defects and heavy alcohol use. ${ }^{[2]}$ It is important to further identify risk factors and precipitants of atrial fibrillation given its association with significant morbidity and mortality.

\section{Case presentation}

A 50-year-old male presented to the emergency department after an electrocardiogram (ECG) in his primary care providers office revealed atrial fibrillation with rapid ventric- ular response. The ECG was preformed as part of a preoperative evaluation for an upcoming orthopedic surgery. He was hemodynamically stable with a blood pressure of 143/108 He was asymptomatic and denied any chest pain, shortness of breath, palpitations or syncope. On further history, he was found to have recently been started on amphetaminedextroamphetamine 25 milligrams twice daily for a new diagnosis of attention deficit hyperactivity disorder (ADHD) approximately three months prior. He had no known structural heart disease, coronary artery disease, cardiac arrhythmia or hypertension. He denied use of alcohol, tobacco or illicit substances. Previous ECG from 2008 revealed normal sinus rhythm and he did not have a previous echocardiogram. A subsequent ECG in the emergency department confirmed

\footnotetext{
* Correspondence: Aimee Wehber, MD; Email: awehber@utmck.edu; Address: Graduate School of Medicine, University of Tennessee Medical Center, 1924 Alcoa Highway, U114 Knoxville, Tennessee 37920, USA.
} 
atrial fibrillation with rapid ventricular response, with a heart rate of 121 beats per minute (see Figure 1). Further laboratory testing demonstrated potassium level $4.6 \mathrm{mEq} / \mathrm{L}$ (normal range 3.5-5.3 mEq/L), magnesium level $2.2 \mathrm{mg} / \mathrm{dl}$ (normal range $1.6-2.6 \mathrm{mg} / \mathrm{dl})$, thyroid stimulating hormone 1.490 $\mu \mathrm{IU} / \mathrm{ml}$ (normal range $0.45-4.50 \mu \mathrm{IU} / \mathrm{ml}$ ), free thyroxine $1.28 \mathrm{ng} / \mathrm{dl}$ (normal range $0.82-1.77 \mathrm{ng} / \mathrm{dl}$ ), brain natriuretic peptide $95 \mathrm{pg} / \mathrm{ml}$ (normal range less than $100 \mathrm{pg} / \mathrm{ml}$ ), and troponin $0.03 \mathrm{ng} / \mathrm{ml}$ (normal range $0.00-0.78 \mathrm{ng} / \mathrm{ml}$ ). Chest $\mathrm{X}$-ray was without acute findings.

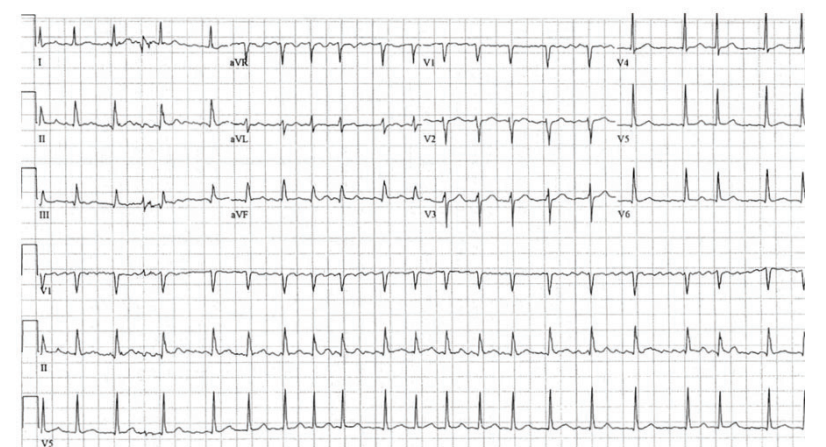

Figure 1. Atrial fibrillation with rapid ventricular response

Diltiazem $10 \mathrm{mg}$ bolus and continuous infusion were initiated, and did control his heart rate. Transesophageal echocardiogram (TEE) was performed, was unrevealing for thrombus, and subsequent direct current cardioversion with 120 joules biphasic energy successfully restored normal sinus rhythm. Echocardiogram, while in atrial fibrillation, revealed an ejection fraction of $40 \%-45 \%$, mild global hypokinesis of the left ventricle, and mild mitral regurgitation. He was asked to follow up outpatient for a repeat echocardiogram to re-evaluate his ejection fraction in normal sinus rhythm. The amphetamine-dextroamphetamine was discontinued and he was started on diltiazem $120 \mathrm{mg} / 24$ hours extended release once daily.

At his two-month follow up, a repeat transthoracic echocardiogram was obtained to re-evaluate left ventricular ejection fraction. Echocardiogram revealed normal sinus rhythm with a normal left ventricular ejection fraction of 55\%-60\% and no wall motion abnormalities. Given the rapid resolution of normal systolic function, it was presumed his reduced ejection fraction previously was secondary to his atrial fibrillation at the time the echocardiogram was performed. Ejection fraction is frequently underestimated via ultrasound if patient is in atrial fibrillation. An additional possibility is the low ejection fraction was a result of atrial fibrillation-induced cardiomyopathy, which resolved upon restoration of sinus rhythm. Nevertheless, it is very unlikely that the depressed systolic function was secondary to underlying structural heart disease that coincidently resolved.

\section{Discussion}

Amphetamine-dextroamphetamine, trade name Adderall, is a salt combination widely used for the treatment of ADHD. It is a noncatecholamine sympathomimetic central nervous system (CNS) stimulant, and a class II controlled substance. The Food and Drug Administration (FDA) label for Adderall gives warning of serious cardiovascular events and risk of sudden death in patients with structural heart disease or other serious cardiac conditions. It is contraindicated in patients with moderate to severe hypertension, symptomatic cardiovascular conditions, advanced arteriosclerosis, and hyperthyroidism due to the risk of major cardiovascular events in this population. ${ }^{[3]}$

Literature review was unrevealing for linkage of amphetamine stimulants to atrial fibrillation specifically. However, there are reports associating amphetamines to atrial flutter. $^{[4]}$ Additionally, recreational use of amphetamines can cause electrical instability of the myocardium potentially leading to arrhythmias, although this is more typical in the setting of an underlying structural heart defect. ${ }^{[5]}$

It was evident that there is an association between increased heart rate and blood pressure in adults using these medications secondary to increased sympathetic tone. Meta-analysis revealed the average heart rate was increased by approximately 5 beats per minute $([3.6,7.8], p<.001)$ with an average increase in systolic blood pressure of $2.0 \mathrm{mmHg}$ $([0.8,3.2], p=.005)$ using CNS stimulants, and there was only a small risk of significant cardiovascular events of less than $5 \% .^{[6]}$

Hypertension and increased pulse pressure are independent risk factors for development of atrial fibrillation. ${ }^{[2]}$ Given that amphetamines are linked to an increase in systolic blood pressure, it seems plausible that there could be a correlation between these medications and the development of atrial fibrillation, but further investigation linking the two is crucial.

Other medications that have been shown to induce atrial fibrillation include dopamine agonists, cholinergic agents, adenosine, sympathomimetic inhalers (bronchodilators), antipsychotics, antidepressants, and corticosteroids. ${ }^{[2]}$

A limitation to the paucity of data regarding CNS stimulant use is the emergence of use of these medications recreationally and for performance enhancement. On presentation with new onset atrial fibrillation, patients may not offer information regarding the illegal use of these medications during the history and physical. We must rely on the diligence of the practitioner to evaluate all possible causes for a new onset arrhythmia, and possibly specifically ask about the off label use of these medications.

ISSN 2332-7243 E-ISSN 2332-7251 
It is very important to keep pursuing possible explanations for causes of lone atrial fibrillation, as the prevalence is increasing and is expected to continue to increase in the future. ${ }^{[1]}$ There is a large cost involved in treating these conditions as well as their sequela.

\section{Conclusion}

There is clear documentation in the literature regarding myocardial infarction, stroke, and sudden death in adults using CNS stimulants. However, there is little data regarding spe- cific arrhythmias, including atrial fibrillation, using these medications. Further studies need to be developed to assess the relationship between stimulant medications and atrial fibrillation, as well as guidelines for prescribing these medications to patients who may already be at risk for developing atrial fibrillation based on personal or family history. Animal models may be helpful in determining linkage between these medications and arrhythmias as well as review of patients with lone atrial fibrillation directed at medication review.

\section{REFERENCES}

[1] Wilke T, Groth A, Mueller S, et al. Incidence and prevalence of atrial fibrillation: an analysis based on 8.3 million patients. Eurospace. 2012; 15(4): 486-493. PMid:23220354 http://dx.doi.org/10. 1093/europace/eus333

[2] Potpara TS, Lip GYH. Lone atrial fibrillation: what is known and what is to come. Int J Clin Pract. 2011; 65(4): 446-457. PMid:21219558 http://dx.doi.org/10.1111/j.1742-1241. $2010.02618 . \mathrm{x}$

[3] Adderall (CII). Food and Drug Administration. 2007; NDA 11-522/S040 .

[4] Mugmon M. Atrial flutter with aberrant conduction in a patient taking amphetamine salts and caffeine. Journal of Community Hospital Internal Medicine Perspectives. 2011; 1: 10663. http://dx.doi.o rg/10.3402/jchimp.v1i4.10663

[5] Ghuran A, Nolan J. The cardiac complications of recreational drug use. West J Med. 2000; 173(6): 412-415. PMid:11112762 http://dx.doi.org/10.1136/ewjm.173.6.412

[6] Mick E, McManus MD, Goldberb RJ. Meta-Analysis of Increased Heart Rate and Blood Pressure Associated with CNS Stimulant Treatment of ADHD in Adults. Eur Neuropsychopharmacol. 2013; 23(6): 534-541. PMid:22796229 http://dx.doi.org/10.1016/j.eur oneuro.2012.06.011 